\title{
New taxa of oribatid mites from Korup National Park (Cameroon). The genus Pilizetes (Acari, Oribatida, Galumnidae)
}

\author{
SERGEY G. ERMILOV ${ }^{1 *}$, JOSEF STARÝ ${ }^{2}$ \& JENÖ KONTSCHÁN ${ }^{3}$ \\ ${ }^{1}$ Tyumen State University, Tyumen, Russia. E-mail: ermilovacari@yandex.ru \\ ${ }^{2}$ Biology Centre v.v.i., Czech Academy of Sciences, Institute of Soil Biology, České Budèjovice, Czech Republic. E-mail: \\ jstary@upb.cas.cz \\ ${ }^{3}$ Center for Agricultural Research, Plant Protection Institute, Hungarian Academy of Sciences, Budapest, Hungary. E-mail: \\ jkontschan@gmail.com \\ *Corresponding author
}

\begin{abstract}
Two new species of oribatid mites of the genus Pilizetes (Oribatida, Galumnidae) are described from litter and soil in the Korup National Park (Cameroon). Pilizetes paradudichi sp. nov. differs from Pilizetes dudichi Balogh, 1966 by the presence of long interlamellar setae and clearly longer notogastral setae. Pilizetes parasellnicki sp. nov. differs from Pilizetes sellnicki Balogh, 1958 by the presence of thickened, heavily ciliated and long epimeral setae $3 b, 4 a, 4 b$ and $4 c$.
\end{abstract}

Key words: galumnid mites, new species, morphology, systematics, Ethiopian region

\section{Introduction}

During taxonomic identification of oribatid mites (Acari, Oribatida) from the Korup National Park in Cameroon, we found two new species of the genus Pilizetes Sellnick, 1937 (Galumnidae), all from the nominative subgenus. The main goal of our paper is to describe and illustrate these new species. The genus Pilizetes comprises two subgenera and 15 species (Ermilov \& Klimov 2017; see Ermilov \& Koehler 2017 in addition), which are distributed in the Ethiopian region collectively (Subías 2004, updated 2017). The generic and subgeneric diagnoses were presented by Ermilov and Klimov (2017) and Ermilov and Koehler (2017). The identification keys to selective species of Pilizetes were presented by Balogh (1960, 1966), Mahunka (1984), Balogh and Balogh (2002) and Ermilov et al. (2010).

At present, the Cameroonian oribatid mite fauna is poorly investigated, and only one species of the genus Pilizetes is known in this country: P. (Pseudopilizetes) camerunensis Ermilov, 2017 (see Ermilov \& Koehler 2017).

\section{Material and methods}

Material examined. Pilizetes paradudichi sp. nov. (holotype, male; seven paratypes, two females and five males) and Pilizetes parasellnicki sp. nov. (holotype, male; 14 paratypes, three females and 11 males): Cameroon, South-West Province, Korup National Park, Rengo Camp, about 8 km NW of Mundemba, latitude $05^{\circ} 02^{\prime} 11.64^{\prime \prime N}$, longitude 08 49'45.96"E, altitude $300 \mathrm{~m}$, litter and soil sifting sample, 12-16.V.2006 (V.V. Grebennikov). 
Methods. Specimens were mounted in lactic acid on temporary cavity slides for measurement and illustration. Body length was measured in lateral view, from the tip of the rostrum to the posterior edge of the ventral plate. Notogastral width refers to the maximum width of the notogaster in dorsal view (behind pteromorphs). Lengths of body setae were measured in lateral aspect. All body measurements are presented in micrometers. Formulas for leg setation are given in parentheses according to the sequence trochanter-femur-genu-tibia-tarsus (famulus included). Formulas for leg solenidia are given in square brackets according to the sequence genu-tibia-tarsus.

Drawings were made with a camera lucida using a Leica transmission light microscope "Leica DM 2500”.

Morphological terminology used in this paper follows that of F. Grandjean (see Ermilov \& Klimov 2017 for review and application).

The following abbreviations are used: $L$-lamellar line; $S$-sublamellar line; $N$-prodorsal leg niche; $E, T$-lateral ridges of prodorsum; $r$-ridge; $f$-furrow; ro, le, in, $b s$-rostral, lamellar, interlamellar and bothridial setae, respectively; $D$-dorsophragma; $P$ - pleurophragma; $c, l a, l m, l p$, $h, p$ —notogastral setal alveoli; $i a$, ip — notogastral lyrifissures; gla-opisthonotal gland opening; $h$, $m, a$-subcapitular setae; or-adoral seta; $v, l, d, c m, a c m, u l, s u l, v t, l t$ - palp setae; sac-axillary saccule; cha, chb — cheliceral setae; Tg - Trägårdh's organ; Pd I, Pd II - pedotecta I, II, respectively; $1 a, 1 c, 3 b, 4 a, 4 b, 4 c$ - epimeral setae; dis-discidium; $c p$ - circumpedal carina; GP — genital plates; AP — anal plates; $g, a g$, an, ad — genital, aggenital, anal and adanal setae, respectively; iad - adanal lyrifissure; p.o.-preanal organ; Tr, Fe, Ge, Ti, Ta-leg trochanter, femur, genu, tibia, tarsus, respectively; $t$ - tooth; p.a.-leg porose area; $\omega, \sigma, \varphi$ - solenidia; $\varepsilon$-leg famulus; $v, e v, b v, l, d, f t$, tc, it, $p, u, a, s, p v, p l$ - leg setae.

The following abbreviations of collections are used: SMNH-Senckenberg Museum of Natural History, Görlitz, Germany; TSUMZ - Tyumen State University Museum of Zoology, Tyumen, Russia.

\section{Descriptions of new species}

\section{Pilizetes paradudichi sp. nov. (Figs 1-11)}

Diagnosis. Body size: $332-356 \times 232-257$. Surface of notogaster and pteromorphs with system of depressions and ridges between them, forming a reticulate pattern. Prodorsum with system of ridges. Rostral, lamellar and interlamellar setae well developed, le longest. Bothridial setae setiform, dilated in mediodistal part, ciliated. Notogastral porose areas and saccules absent. Notogastral setae of medium size, bacilliform, heavily barbed; pteromorphal setae not longer than others. Median pore absent. Epimeral setal formula: 1-0-1-3; $3 b$ and $4 a$ bacilliform, heavily barbed, others thin and setiform, slightly barbed. Genital setae setiform, slightly barbed; aggenital, anal and adanal setae erect, barbed.

Description. Measurements. Body length: 332 (holotype), 332-356 (7 paratypes); notogaster width: 240 (holotype), 232-257 (7 paratypes). No differences between females and males in body size.

Integument (Figs 1-4, 10, 11). Body brown to light yellow-brownish. Body surface densely microtuberculate (diameter of tubercles up to 2). Subcapitular mentum, genital and anal plates and margins of pteromorphs foveolate; foveolae on GP (up tp 8) larger than others (up to 2). Lateral sides of prodorsum slightly microgranulate.

Prodorsum (Figs 1-3). With well-developed system of ridges. Rostrum broadly rounded, with deep transverse furrow. Lamellar lines thickened, sublamellar lines thin, both parallel, curving 
backwards at ventral ends. Prodorsal leg niches and lateral ridges of prodorsum well-developed. Rostral (53-57), lamellar (77-82) and interlamellar (49-53) setae setiform, ro and in barbed, le densely ciliated; ro thinnest. Bothridial setae (110-118) setiform, but distinctly dilated in mediodistal part, ciliated. Exobothridial setae and sejugal porose areas absent. Dorsophragmata slightly visible.

Notogaster (Figs 1-4). Notogaster and pteromorphs with system of depressions and ridges, forming a reticulate pattern. Porose areas and saccules absent. With 10 pairs of bacilliform, heavily barbed setae, $p_{1}-p_{3}(41-45)$ shorter than others (53-61). Median pore absent. Lyrifissures (except distinct $i a$; and $i p$ located between $p_{1}$ and $p_{2}$ ) not visible. Opisthonotal gland openings small, located lateral to $h_{2}$ and distanced from them.

Gnathosoma (Figs 5-7). Subcapitulum size: 102-110 × 90-98. Subcapitular setae setiform, smooth, $a(16)$ longer than $m$ and $h(10-12)$. Adoral setae (10-12) setiform, barbed. Length of palps: 65-69. Postpalpal setae (6) spiniform, smooth. Length of chelicerae: 118-127. Cheliceral setae setiform, barbed, cha (41-49) longer than chb (26-32). Trägårdh's organ of chelicerae long, elongate triangular.

Epimeral and lateral podosomal regions (Figs 2, 3). Anterior tectum of epimere I smooth. Pedotecta I and II rounded in ventral view. Discidia triangular, rounded distally. Epimeral setal formula: 1-0-1-3. Epimeral setae $3 b(53-57)$ and $4 a(45-49)$ bacilliform, heavily barbed, $1 a, 4 b(14-16)$ and $4 c$ (20) setiform, slightly barbed. Circumpedal carinae long, reaching the level of pedotecta I.

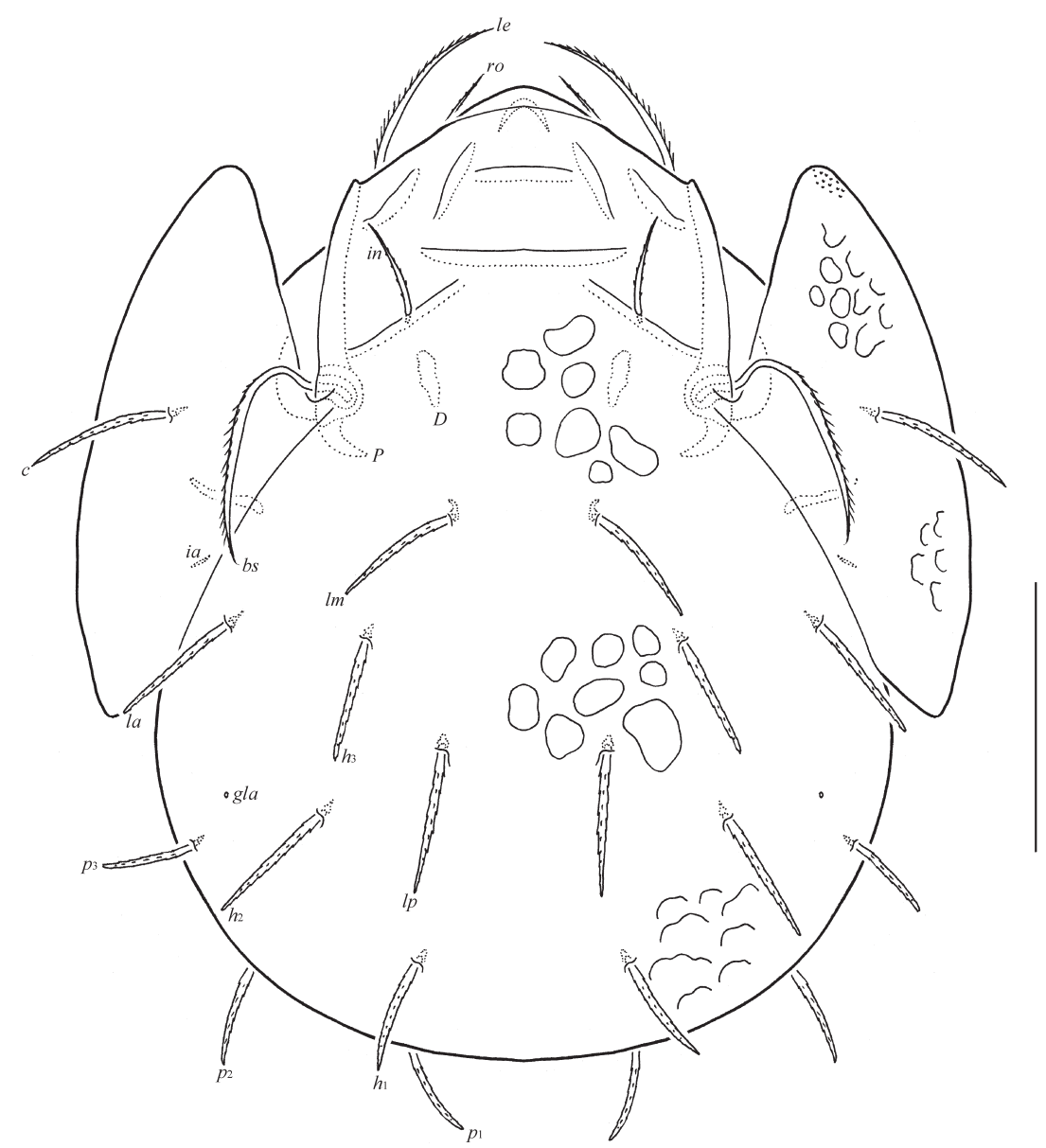

FIGURE 1. Pilizetes paradudichi sp. nov., adult: dorsal view (legs not shown). Scale bar $100 \mu \mathrm{m}$. 


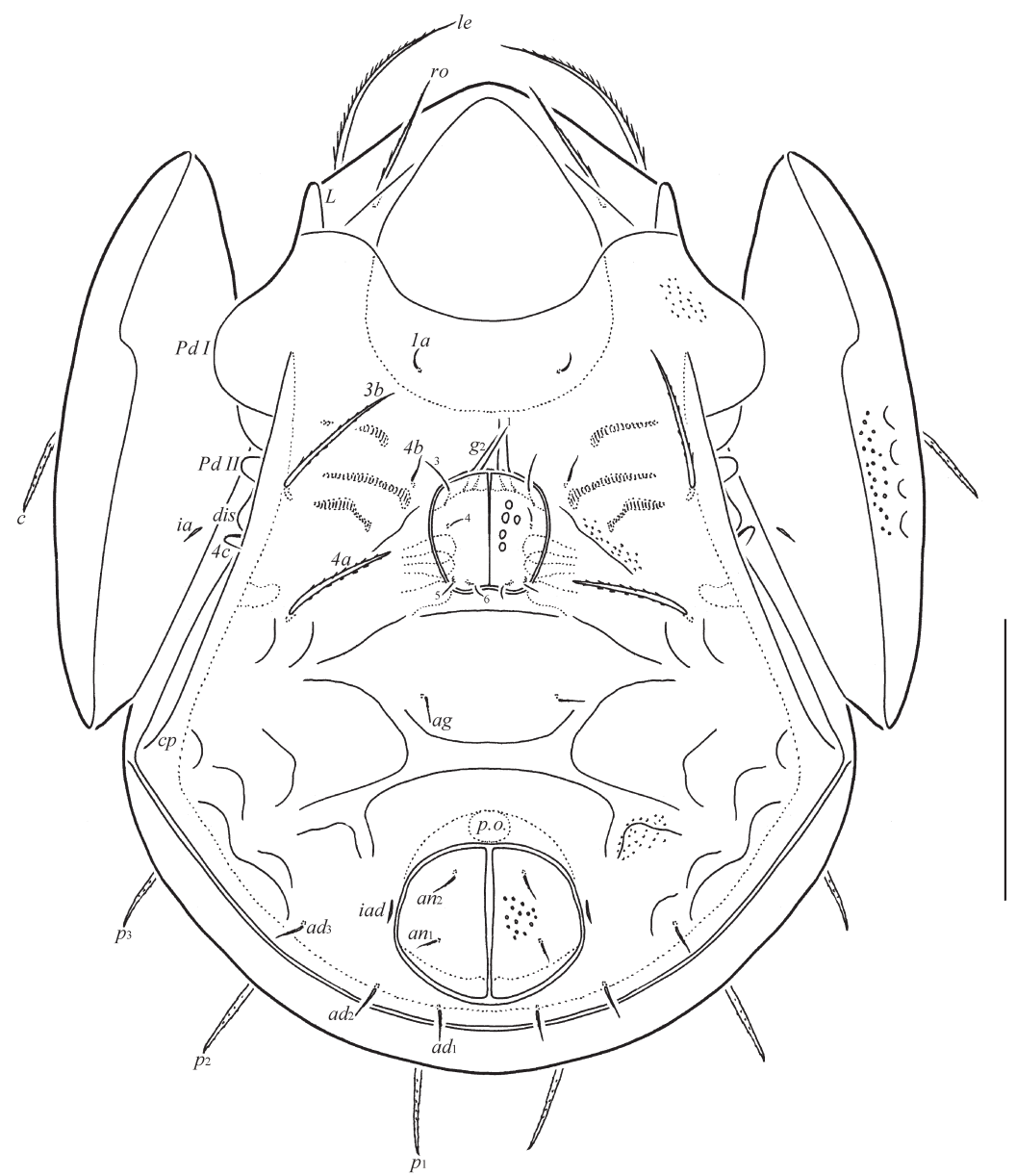

FIGURE 2. Pilizetes paradudichi sp. nov., adult: ventral view (gnathosoma and legs not shown). Scale bar 100 $\mu \mathrm{m}$.

TABLE 1. Leg setation and solenidia of adult Pilizetes paradudichi sp. nov. and P. parasellnicki sp. nov.

\begin{tabular}{llllll}
\hline Leg & Tr & Fe & Ge & Ti & Ta \\
\hline I & $v^{\prime}$ & $d,(l), b v^{\prime}$ & $(l), v^{\prime}, \sigma$ & $(l),(v), \varphi_{1}, \varphi_{2}$ & $(f t),(t c),(i t),(p),(u),(a), s,(p v), v^{\prime},(p l), l^{\prime}, \varepsilon, \omega_{1}, \omega_{2}$ \\
II & $v^{\prime}$ & $d,(l), b v^{\prime \prime}$ & $(l), v^{\prime}, \sigma$ & $(l),(v), \varphi$ & $(f t),(t c),(i t),(p),(u),(a), s,(p v), \omega_{1}, \omega_{2}$ \\
III & $v^{\prime}$ & $d, e v^{\prime}$ & $l^{\prime}, \sigma$ & $l^{\prime},(v), \varphi$ & $(f t),(t c),(i t),(p),(u),(a), s,(p v)$ \\
IV & $v^{\prime}$ & $d, e v^{\prime}$ & $d, l^{\prime}$ & $l^{\prime},(v), \varphi$ & $f t^{\prime \prime},(t c),(p),(u),(a), s,(p v)$ \\
\hline
\end{tabular}

Roman letters refer to normal setae, Greek letters to solenidia (except $\varepsilon=$ famulus). Single prime (') marks setae on anterior and double prime (") setae on posterior side of the given leg segment. Parentheses refer to a pair of setae.

Anogenital region (Figs 2-4, 10, 11). With specific system of depressions, bordered by thick ridges (see Figs. 2, 10, 11). Six pairs of genital setae $\left(g_{1}, 24 ; g_{2}, 20 ; g_{3}, 16 ; g_{4}-g_{6}, 6-8\right)$ setiform, slightly barbed. One pair of aggenital (16), two pairs of anal (12) and three pairs of adanal (16) setae setiform, erect, barbed. Anterior edge of genital plates with three setae. Aggenital setae equal distanced from genital and anal plates. Adanal lyrifissures located parallel and close to anal plates. Adanal setae $a d_{1}$ posterior, $a d_{2}$ posterolateral, $a d_{3}$ lateral to anal aperture and located close to margin of the ventral plate. Distance $a d_{1}-a d_{2}$ equal to $a d_{2}-a d_{3}$. 

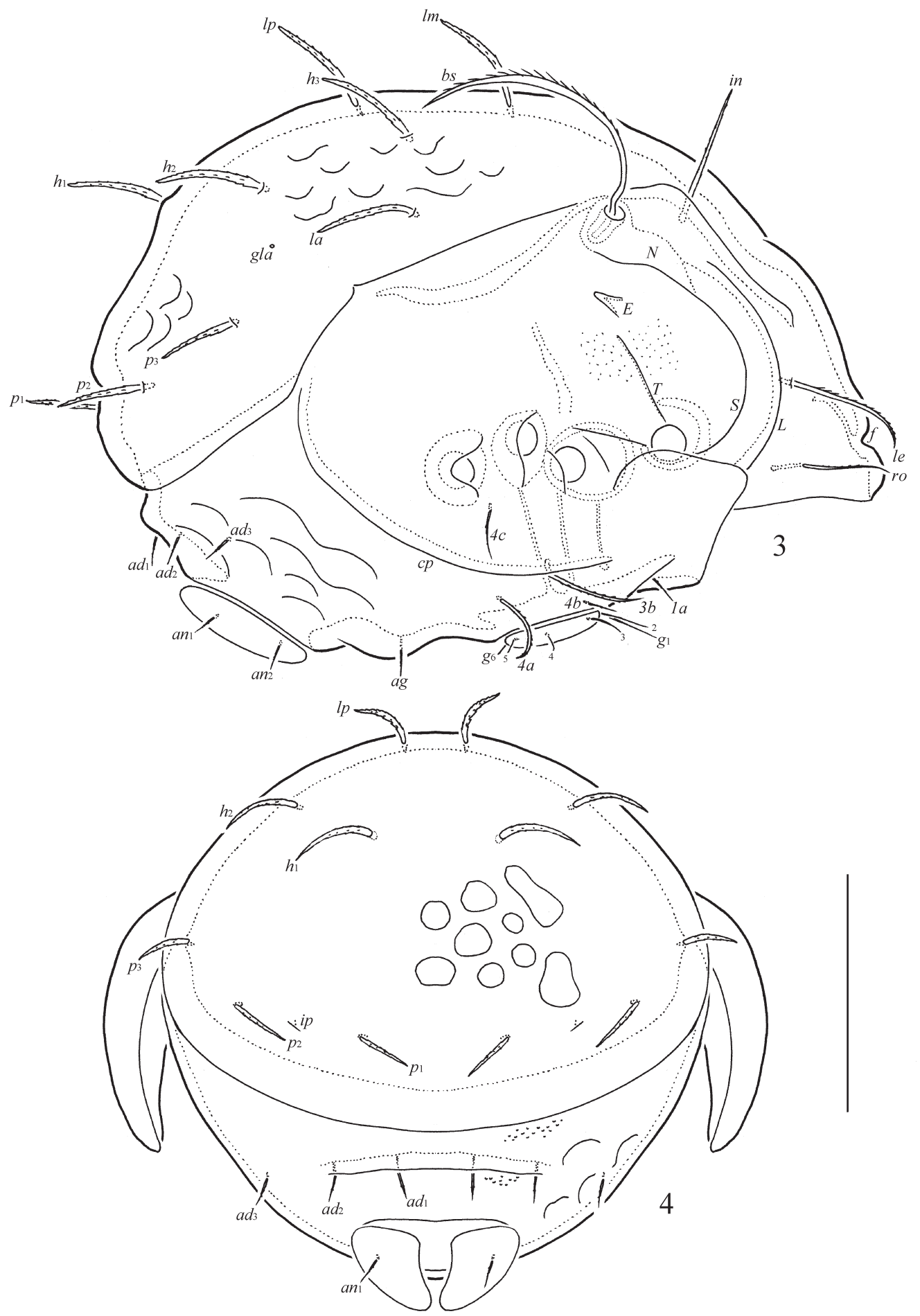

FIGURES 3-4. Pilizetes paradudichi sp. nov., adult: 3-lateral view (pteromorph, gnathosoma and legs not shown); 4 - posterior view. Scale bar $100 \mu \mathrm{m}$. 


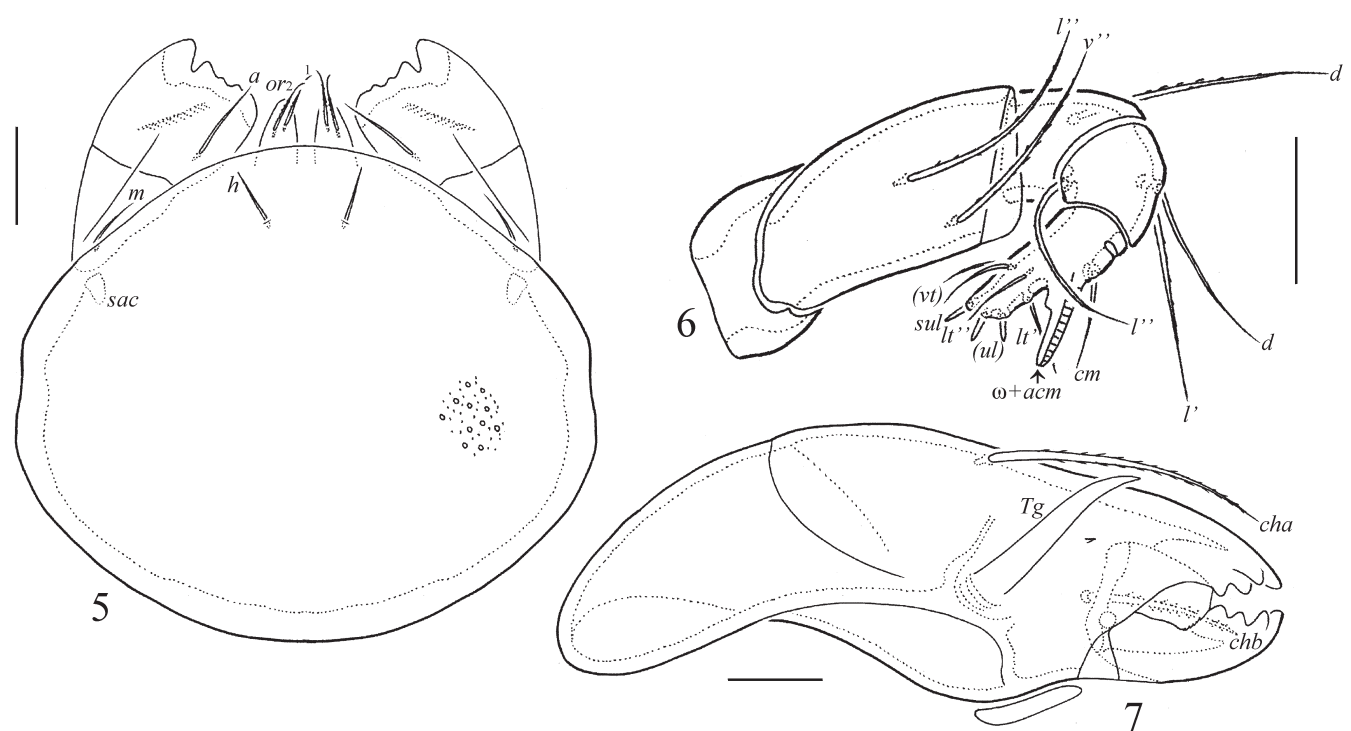

FIGURES 5-7. Pilizetes paradudichi sp. nov., adult: 5-subcapitulum, ventral view; 6-palp, right, antiaxial view; 7 -chelicera, right, antiaxial view. Scale bars $17 \mu \mathrm{m}(5,7), 15 \mu \mathrm{m}(6)$.

Legs (Figs 8, 9). Median claw distinctly thicker than laterals, all slightly barbed on dorsal side. Genua IV with anterodorsal tooth. Porose areas on all femora and on trochanters III, IV poorly visible. Formulas of leg setation and solenidia: I (1-4-3-4-20) [1-2-2], II (1-4-3-4-15) [1-1-2], III (12-1-3-15) [1-1-0], IV (1-2-2-3-12) [0-1-0]; homologies of setae and solenidia indicated in Table 1. Famulus on tarsi I inserted posterolateral to solenidion $\omega_{1}$. Solenidion on tibiae IV inserted in anterior part of the segment.

Type deposition. The holotype (in ethanol with drop of glycerol) and three paratypes (in ethanol with drop of glycerol) are deposited in the collection of SMNH. Four paratypes (in ethanol with drop of glycerol) are deposited in the collection of TSUMZ.

Etymology. The specific name paradudichi refers to the similarity of the new species to the species Pilizetes dudichi Balogh, 1966.

Remarks. In having notogaster and pteromorphs with system of depressions and ridges between them, forming a reticulate pattern, Pilizetes paradudichi sp. nov. is morphologically most similar to Pilizetes dudichi Balogh, 1966 from Chad (see Balogh 1966), but differs by the presence of long interlamellar setae (vs. short in $P$. dudichi) and longer notogastral setae, $l m$ reaching insertions of $h_{3}$ (vs. shorter, $l m$ clearly not reaching insertions of $h_{3}$ in $P$. dudichi).

\section{Pilizetes parasellnicki sp. nov. (Figs 12-22)}

Diagnosis. Body size: 390-398 $\times$ 265-290. Body surface foveolate. Prodorsum with one pair of longitudinal ridges between lamellar setae. Rostral, lamellar and interlamellar setae well developed; ro shortest. Bothridial setae setiform, dilated in mediodistal part, slightly barbed. Notogastral porose areas and saccules absent. Setae of notogaster of medium size, bacilliform, heavily barbed; pteromorphal setae distinctly longer, setiform, slightly barbed. Median pore present. Epimeral setal formula: 2-0-1-3; $1 a$ setiform, barbed, $3 b, 4 a, 4 b$ and $4 c$ thickened, heavily ciliated. Genital and aggenital setae setiform, erect, slightly barbed, anal and adanal setae bacilliform, barbed; ad longest. 


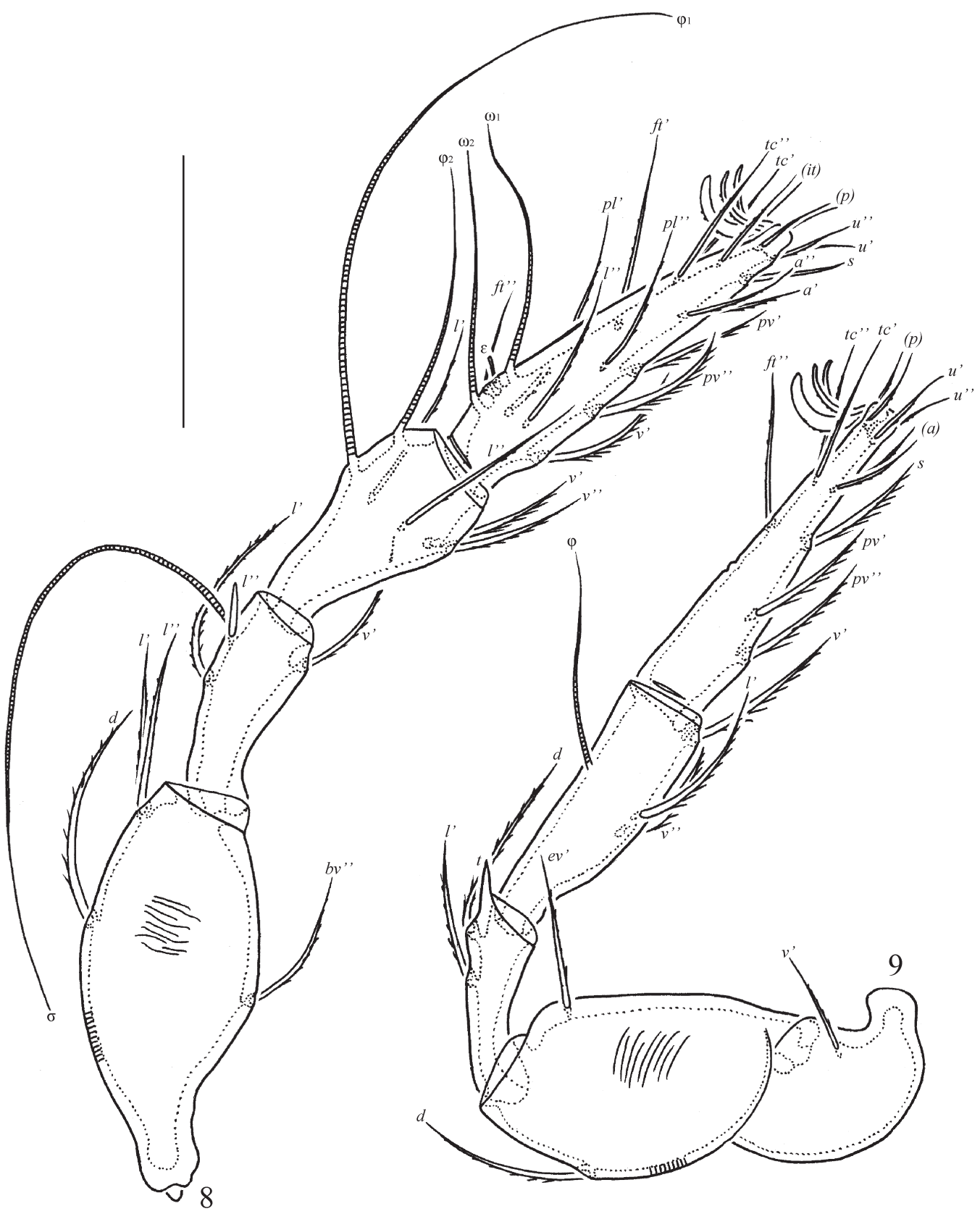

FIGURES 8-9. Pilizetes paradudichi sp. nov., adult: 8-leg I, without trochanter, right, antiaxial view; 9-leg IV, left, antiaxial view. Scale bar $50 \mu \mathrm{m}$.

Description. Measurements. Body length: 398 (holotype), 390-398 (14 paratypes); notogaster width: 282 (holotype), 265-290 (14 paratypes). No differences between females and males in body size. 


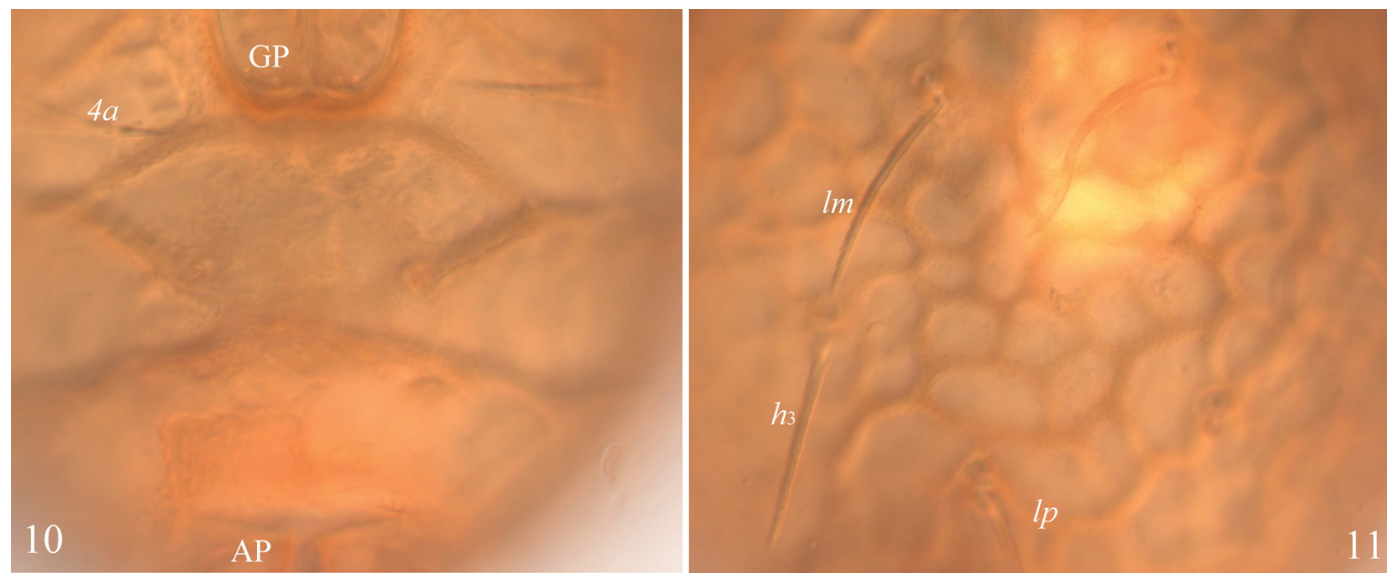

FIGURES 10-11. Pilizetes paradudichi sp. nov., adult, microscope images: 10 - part of anogenital region; 11 - part of notogaster.

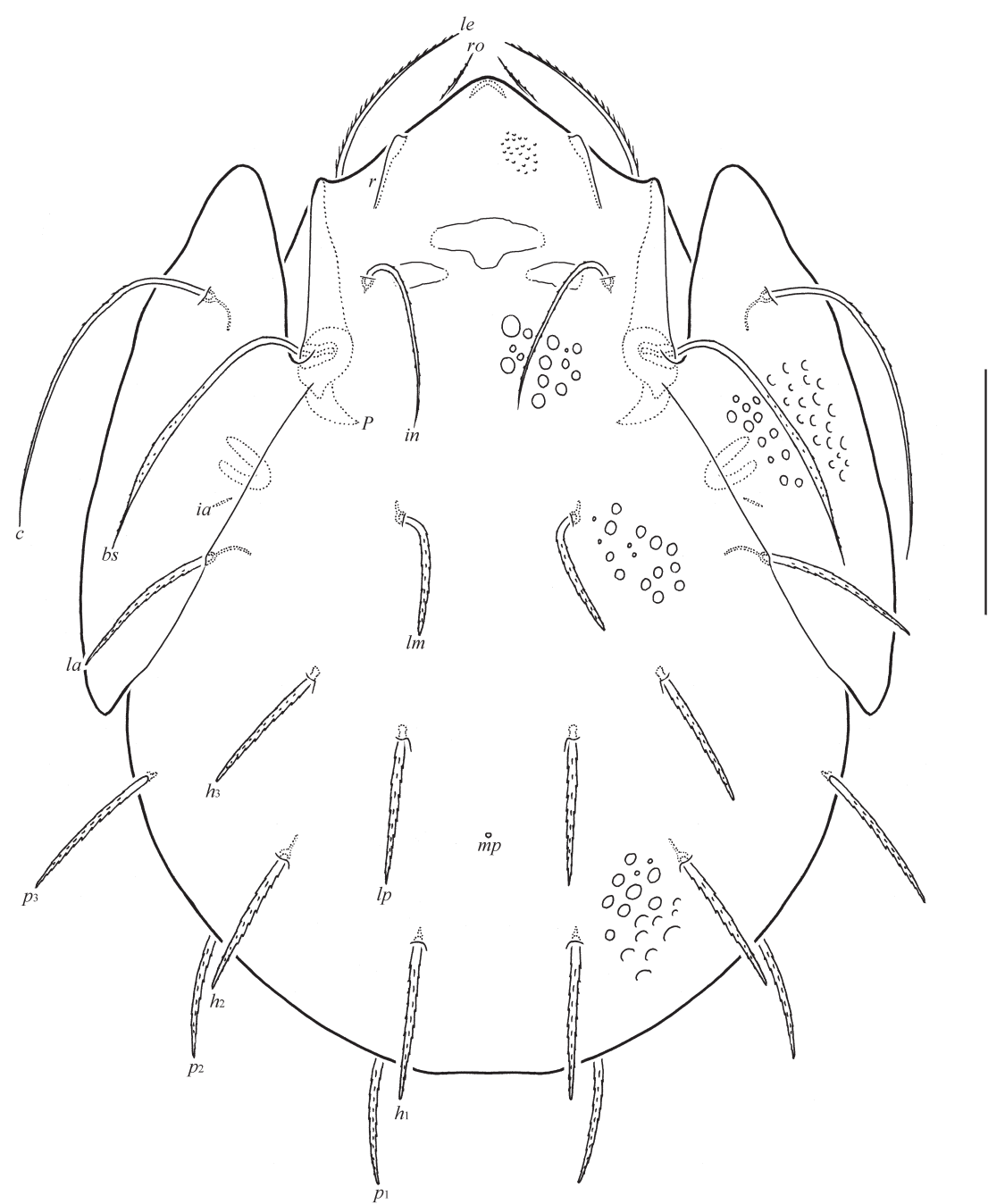

FIGURE 12. Pilizetes parasellnicki sp. nov., adult: dorsal view (legs not shown). Scale bar $100 \mu \mathrm{m}$. 


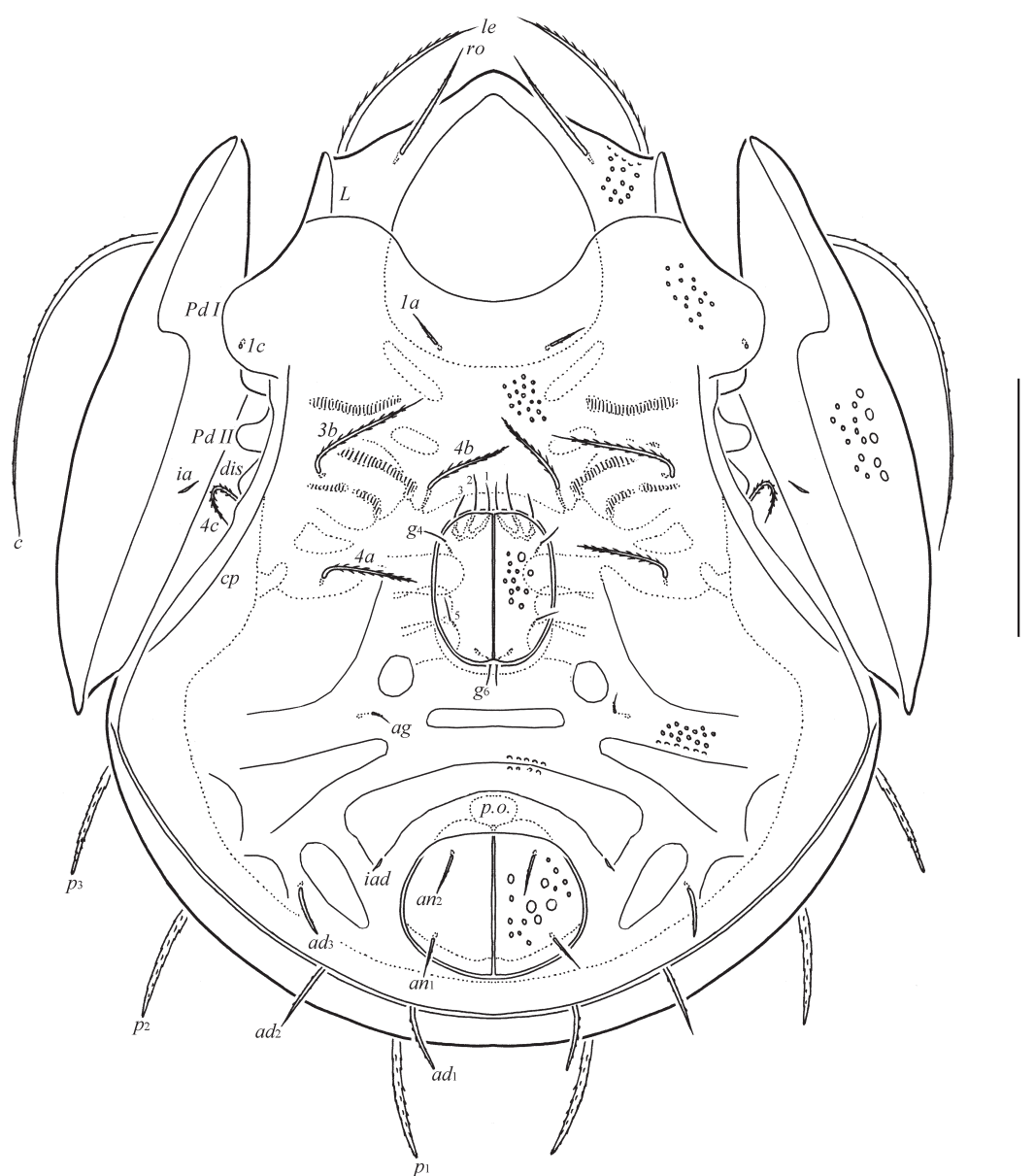

FIGURE 13. Pilizetes parasellnicki sp. nov., adult: ventral view (gnathosoma and legs not shown). Scale bar $100 \mu \mathrm{m}$.

Integument (Figs 12-16, 21). Body brown to light yellow-brownish. Body surface (including subcapitular mentum and genital and anal plates) foveolate; foveolae on prodorsum and ventral side (up to 4 ) smaller than on notogaster and pteromorphs (up to 12). Lateral sides of prodorsum slightly microgranulate.

Prodorsum (Figs 12-14). Rostrum broadly rounded. With one pair of strong longitudinal ridges in the middle part and three small depressions between interlamellar setae. Lamellar lines thickened, sublamellar lines thin, both parallel, curving backwards at ventral ends. Prodorsal leg niches and lateral ridges of prodorsum well-developed. Rostral (53-65), lamellar (82-90) and interlamellar (8290) setae setiform, ro and in barbed, le densely ciliated; ro thinnest. Bothridial setae (118-135) setiform, but distinctly dilated in mediodistal part, slightly barbed. Exobothridial setae and sejugal porose areas absent. Dorsophragmata not visible.

Notogaster (Figs 12-15). Porose areas and saccules absent. With 10 pairs of setae, $c$ very long (127-141), setiform, slightly barbed, others of medium size (57-65), bacilliform, heavily barbed. Median pore present, located between insertions of setae $h_{2}$. All lyrifissures (except distinct $i a$ ) and opisthonotal gland openings not visible.

Gnathosoma (Figs 16-18). Subcapitulum size: 102-110 × 90-98. Subcapitular setae setiform, smooth, $a$ (14) longer than $m$ and $h$ (10). Adoral setae (10) setiform, barbed. Length of palps: 69-77. 
Postpalpal setae (6) spiniform, smooth. Length of chelicerae: 123-135. Cheliceral setae setiform, barbed, cha (36-45) longer than chb (24-28). Trägårdh's organ of chelicerae long, elongate triangular.

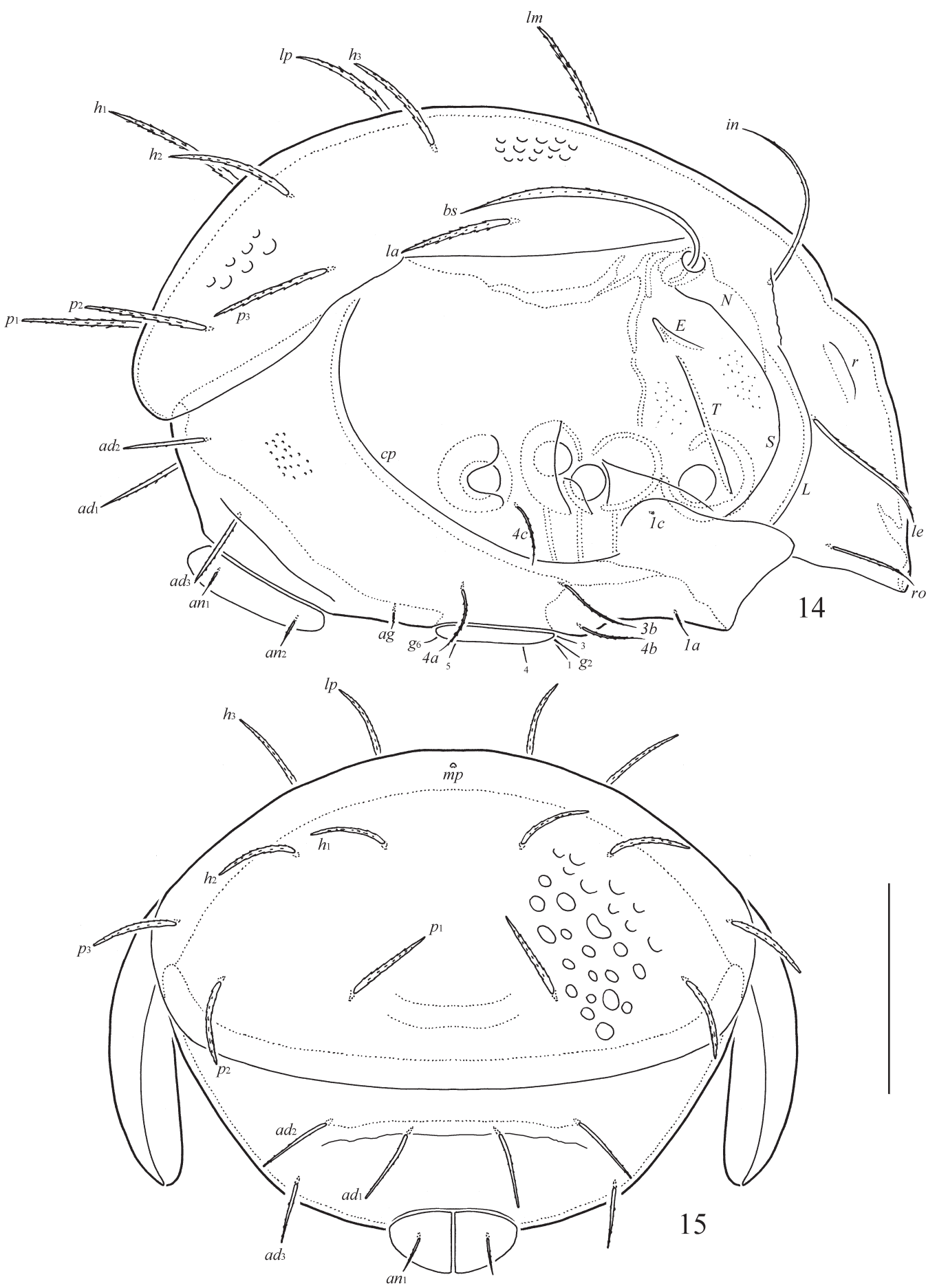

FIGURES 14-15. Pilizetes parasellnicki sp. nov., adult: 14-lateral view (pteromorph, gnathosoma and legs not shown); 15 - posterior view. Scale bar $100 \mu \mathrm{m}$. 

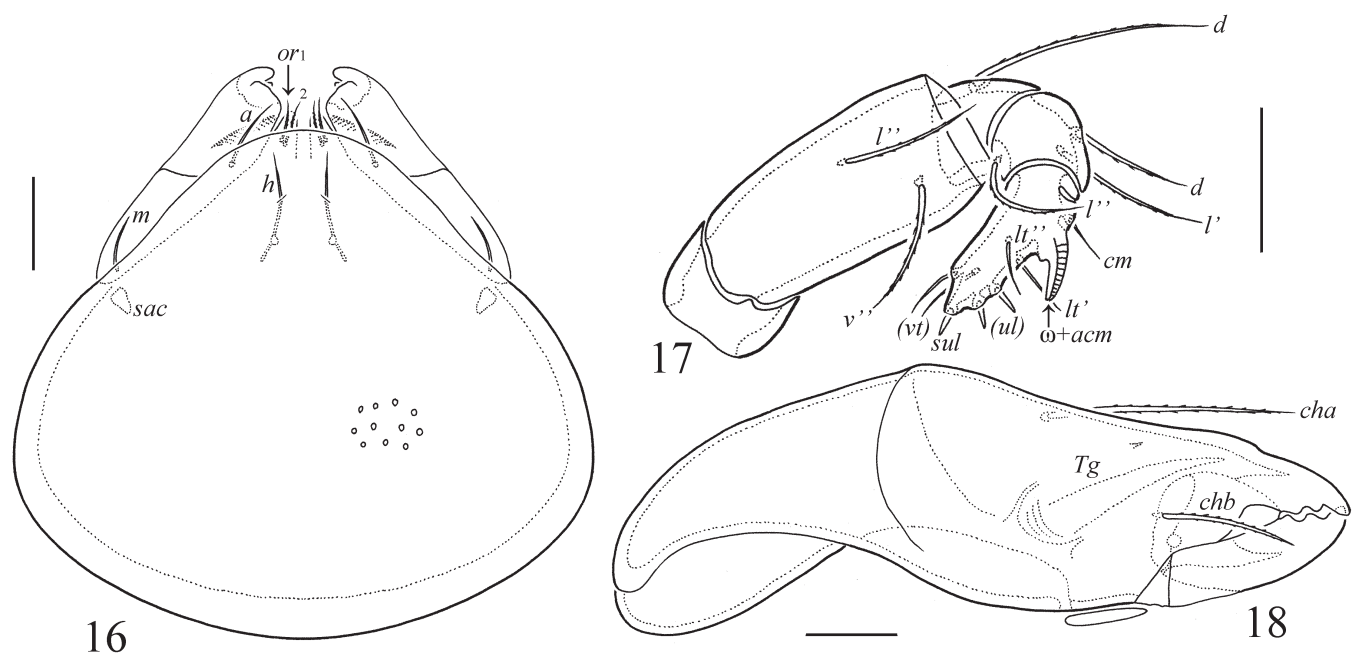

FIGURES 16-18. Pilizetes parasellnicki sp. nov., adult: 16-subcapitulum, ventral view; 17-palp, right, antiaxial view; 18 — chelicera, right, antiaxial view. Scale bars $17 \mu \mathrm{m}(16,18), 15 \mu \mathrm{m}(17)$.

Epimeral and lateral podosomal regions (Figs 13, 14). Anterior tectum of epimere I smooth. Pedotecta I and II rounded in ventral view. Discidia triangular, rounded distally. Epimeral setal formula: 2-0-1-3. Epimeral setae $1 c$ represented by alveoli, $1 a(12-16)$ setiform, erect, barbed, $3 b$ (53-57), $4 a, 4 b$ and $4 c$ (32-41) thickened, heavily ciliated. Circumpedal carinae long, reaching the level of pedotecta I.

Anogenital region (Figs 13-15, 21, 22). With specific system of depressions, which are bordered by thick ridges (see Figs 13, 21, 22). Six pairs of genital $\left(g_{1}, g_{3}-g_{6}, 8-10 ; g_{2}, 12-14\right)$ and one pair of aggenital (8-10) setae setiform, erect, slightly barbed. Anterior edge of genital plates with three setae. Aggenital setae located closer to genital plates than to anal plates. Two pairs of anal (20-28) and three pairs of adanal $\left(a d_{1}, a d_{2}, 41-45 ; a d_{3}, 28-36\right)$ setae bacilliform, barbed. Adanal lyrifissures located parallel to anal plates and slightly distanced from them. Adanal setae $a d_{1}$ posterior, $a d_{2}$ posterolateral, $a d_{3}$ lateral to anal aperture and located close to margin of the ventral plate. Distance $a d_{1}-a d_{2}$ equal to $a d_{2}-a d_{3}$.

Legs (Figs 19,20). Median claw distinctly thicker than laterals, all slightly barbed on dorsal side. Genua IV with anterodorsal tooth. Porose areas on all femora and on trochanters III, IV poorly visible. Formulas of leg setation and solenidia: I (1-4-3-4-20) [1-2-2], II (1-4-3-4-15) [1-1-2], III (12-1-3-15) [1-1-0], IV (1-2-2-3-12) [0-1-0]; homologies of setae and solenidia indicated in Table 1. Famulus on tarsi I inserted posterolateral to solenidion $\omega_{1}$. Solenidion on tibiae IV inserted in anterior part of the segment.

Type deposition. The holotype (in ethanol with drop of glycerol) and three paratypes (in ethanol with drop of glycerol) are deposited in the collection of SMNH. Eleven paratypes (in ethanol with drop of glycerol) are deposited in the collection of TSUMZ.

Etymology. The specific name parasellnicki refers to the similarity of the new species to the species Pilizetes sellnicki Balogh, 1958.

Remarks. In general morphological traits (body surface foveolate; porose areas and saccules absent; bothridial setae slightly barbed; setae of notogaster of medium size, pteromorphal setae long, setiform; median pore present'; body of medium size), Pilizetes parasellnicki sp. nov. is morphologically most similar to Pilizetes sellnicki Balogh, 1958 from Angola (see Balogh 1958, 
1960), but differs by the presence of thickened, heavily ciliated and comparatively long epimeral setae $3 b, 4 a, 4 b$ and $4 c$ (vs. simple in $P$. sellnicki).

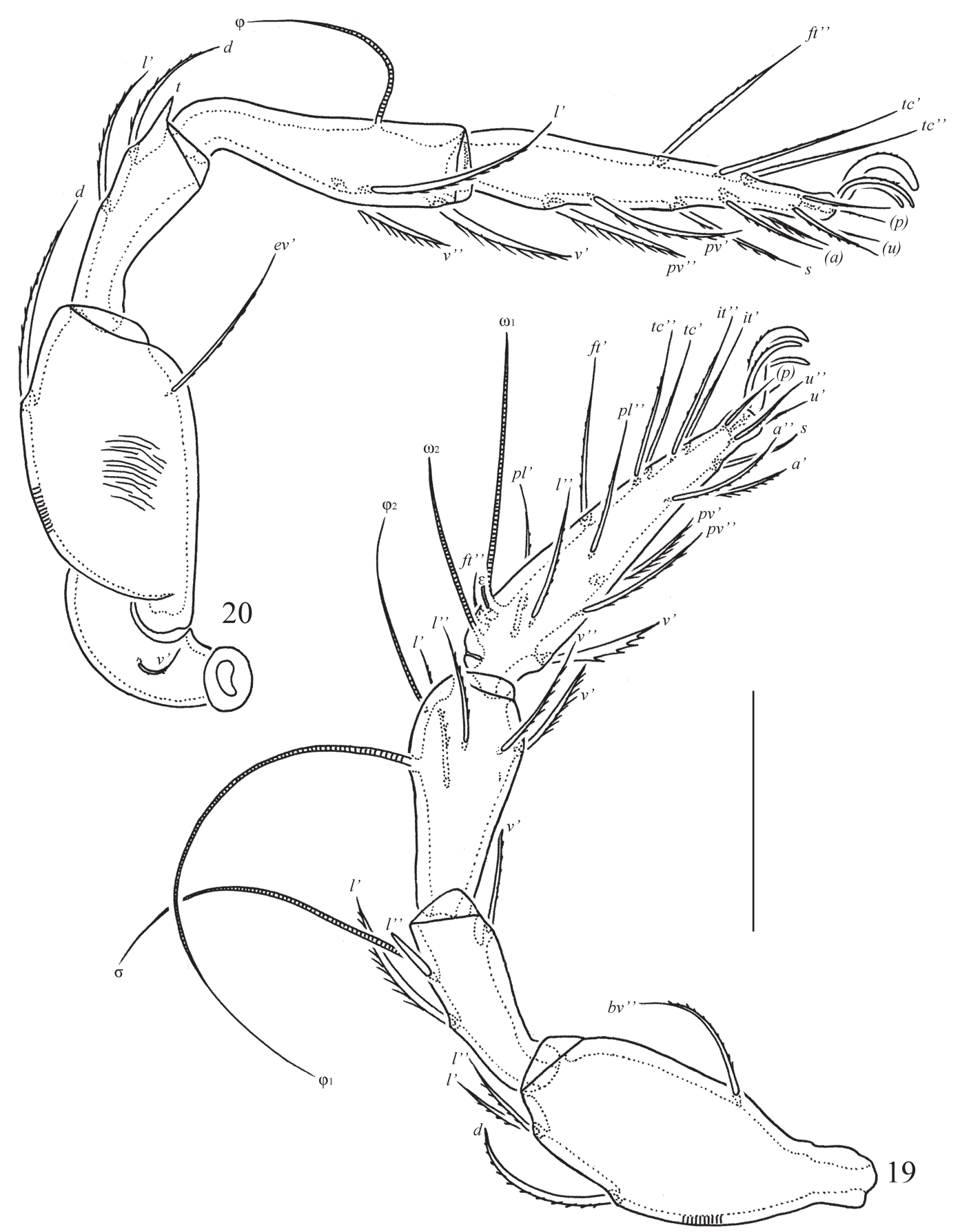

FIGURES 19-20. Pilizetes parasellnicki sp. nov., adult: 19-leg I, without trochanter, right, antiaxial view; 20 - leg IV, left, antiaxial view. Scale bar $50 \mu \mathrm{m}$.

1. Balogh $(1958,1960)$ did not describe and not draw a median pore in Pilizetes sellnicki. We studied the type material from the Hungarian National Museum (Budapest, Hungary) and note that a median pore is present in this species. 


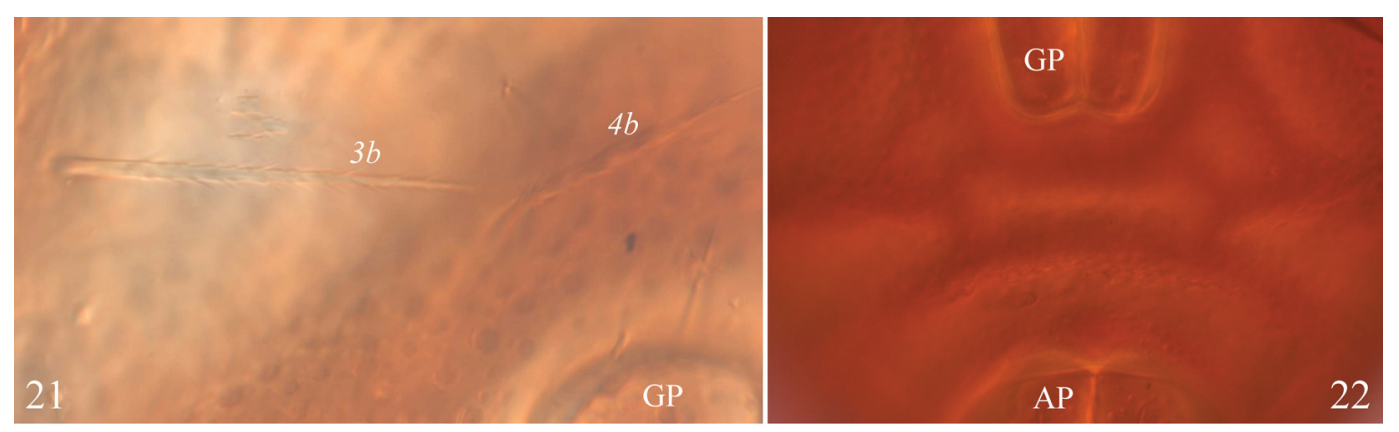

FIGURES 21-22. Pilizetes parasellnicki sp. nov., adult, microscope images: 21—part of epimeral region; 22part of anogenital region.

\section{Acknowledgements}

We cordially thank Dr. Marut Fuangarworn (Chulalongkorn University, Bangkok, Thailand) and two anonymous reviewers for the valuable comments. The reported study was funded by the Russian Foundation for Basic Research (RFBR) according to the research project № 18-04-00096 and by the Academy of Sciences of the Czech Republic, under Research Plan No. AV0Z606960521.

\section{References}

Balogh, J. (1958) Oribatides nouvelles de l'Afrique tropicale. Revue de Zoologie et de Botanique Africaines, $58(1-2), 1-34$.

Balogh, J. (1960) Oribates (Acari) nouveaux d'Angola et du Congo Belge (2ème série). Companhia de Diamantes de Angola, Lisboa, 51, 15-40.

Balogh, J. (1966) On some oribatid mites from Tshad and East Africa collected by Prof. H. Franz, Vienna. Opuscula Zoologica Budapest, 6(1), 69-77.

Balogh, J. \& Balogh, P. (2002) Identification keys to the oribatid mites of the Extra-Holarctic regions. Vol. 1. Miskolc, Well-Press Publishing Limited, 453 pp.

Ermilov, S.G. \& Klimov, P.B. (2017) Generic revision of the large-winged mite superfamily Galumnoidea (Acari, Oribatida) of the world. Zootaxa, 4357(1), 1-72. https://doi.org/10.11646/zootaxa.4357.1.1

Ermilov, S.G. \& Koehler, H.H. (2017) New data on oribatid mites (Acari, Oribatida) of Cameroon: results of the Joint German-Cameroonian scientific expedition (April 2016). Systematic \& Applied Acarology, 22(12), 2233-2244.

https://doi.org/10.11158/saa.22.12.13

Ermilov, S.G., Sidorchuk, E.A. \& Rybalov, L.B. (2010) New species of oribatid mites of the superfamily Galumnoidea (Acari: Oribatida) from Ethiopia. Zootaxa, 2646, 43-62.

Mahunka, S. (1984) Oribatids of the Eastern part of the Ethiopian Region (Acari). V. Acta Zoologica Hungarica, 30(1-2), 87-136.

Sellnick, M. (1937) Eine neue Milbe aus Ostafrika. Zoologischer Anzeiger, 117, 130-132.

Subías, L.S. (2004) Listado sistemático, sinonímico y biogeográfico de los ácaros oribátidos (Acariformes: Oribatida) del mundo (excepto fósiles). Graellsia, 60 (número extraordinario), 3-305. Online updated version accessed in February 2017, 598 pp.; http://escalera.bio.ucm.es/usuarios/bba/cont/docs/RO_1.pdf

Submitted: 23 Nov. 2017; accepted by Marut Fuangarworn: 4 Feb. 2018; published: 20 Feb. 2018 